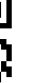

\section{Laparoscopic hepatobiliary and pancreatic surgery: my trials and current status in Korea}

\author{
Sung Su Yun \\ Department of Surgery, Yeungnam University College of Medicine, Daegu, Korea
}

\begin{abstract}
There has been a dramatic change in surgical care over the past 30 years with the introduction of laparoscopic surgery. It was my great fortune that I could experience laparoscopic surgery during my resident training period. After beginning to work for my hospital in 1995, I tried laparoscopic surgery in many surgical fields, including hepatobiliary and pancreatic (HBP), colon, stomach, and vascular surgery (endoscopic saphenous vein harvesting, endoscopic subfascial perforating vein interruption to treat skin complications in patients with deep vein insufficiency in the lower leg). In Sabiston, Textbook of Surgery, published in 1997, laparoscopic Whipple and major liver resection were not accepted at the time but now are. There are three possible reasons that may explain this shift. The first one is the 30 years of experience using advanced techniques; all of us know that "Seeing is believing," and "A thousand hearings are not worth one seeing." Next is the availability of three-dimensional imaging with magnification which enables us to perform difficult surgeries. The last one is the use of good instruments and an advanced surgical platform. In this paper, I would like to share my past and recent trials with advanced HBP laparoscopic surgery, as well as its current status in Korea and future directions.
\end{abstract}

Keywords: Laparoscopy, Minimally invasive surgical procedures, Hepatectomy, Biliary tract surgical procedures, Pancreatectomy

\author{
Received May 6, 2021 \\ Revised May 24, 2021 \\ Accepted May 31, 2021 \\ Corresponding author \\ Sung Su Yun \\ Department of Surgery, Yeungnam \\ University Hospital, 170 \\ Hyeonchung-ro, Nam-gu, Daegu \\ 42415 , Korea \\ Tel: $+82-53-620-3590$ \\ Fax: +82-53-624-113 \\ E-mail: ssyun@med.yu.ac.kr \\ ORCID: \\ https://orcid.org/0000-0002-2726-7165
}

This is an Open Access article distributed under the terms of the Creative Commons Attribution Non-Commercial License (http:// creativecommons.org/licenses/by-nc/4.0/) which permits unrestricted non-commercial use, distribution, and reproduction in any

Copyright (C) The Korean Society of Endomedium, provided the original work is properly cited.

\section{INTRODUCTION}

There has been a dramatic change in surgical care over the past 30 years with the introduction of laparoscopic surgery. It was my great fortune that I could experience laparoscopic surgery during my resident training period. After beginning to work for my hospital in 1995, I tried laparoscopic surgery in many surgical fields, including hepatobiliary and pancreatic (HBP), colon, stomach, and vascular surgery (endoscopic saphenous vein harvesting, endoscopic subfascial perforating vein interruption to treat skin complications in patients with deep vein insufficiency in the lower leg) [1,2].

In Sabiston, Textbook of Surgery, published in 1997, laparoscopic Whipple and major liver resection were not accepted at

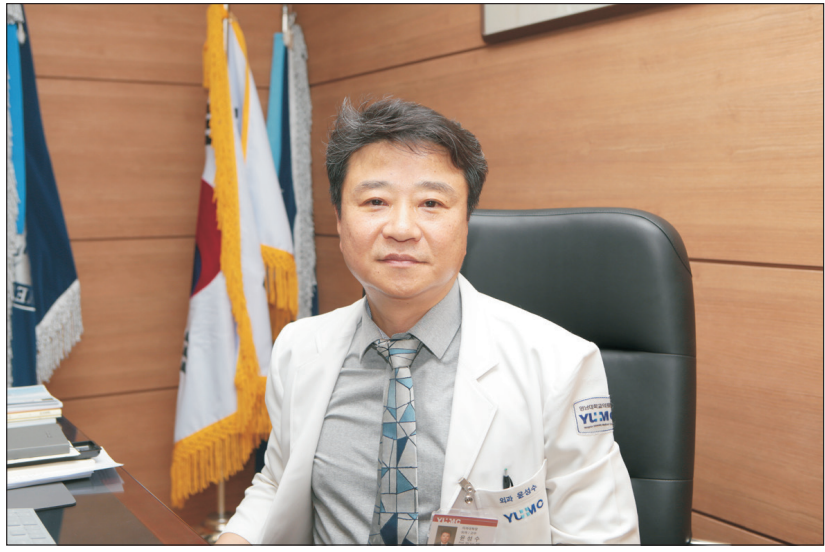

Fig. 1. The 17th president of the Korean Society of Endoscopic and Laparoscopic Surgeons, Prof. Sung Su Yun. 
the time but now are. There are three possible reasons that may explain this shift. The first one is the 30 years of experience using advanced techniques; all of us know that "Seeing is believing," and "A thousand hearings are not worth one seeing." Next is the availability of three-dimensional imaging with magnification which enables us to perform difficult surgeries. The last one is the use of good instruments and an advanced surgical platform.

In this paper, I would like to share my past and recent trials with advanced HBP laparoscopic surgery, as well as its current status in Korea and future directions.

\section{MY TRIALS IN HEPATOBILIARY AND PANCREATIC LAPAROSCOPIC SURGERY}

There was a game-changer who started laparoscopic surgery, the 1 st mover and a fast follower. I think I was one of the fast followers trying to be the 1 st mover (Fig. 1).

How to treat the gallstones: gallbladder, common bile duct, and intrahepatic duct stones

In the early nineties, the explosive success of laparoscopic cholecystectomy (LC) initiated a revolution within general surgery. Eventually, in 1992, the National Institutes of Health consensus meeting accepted LC as a safe and effective treatment of choice for patients with symptomatic gallstones [3]. At that time, we knew the fundamental advantages of LC over open surgery. However, we worried about physiological changes related to $\mathrm{CO}_{2}$ pneumoperitoneum and its application to severe acute cholecystitis and elderly patients with critical comorbidities. In an article published in the Korean Journal of Anesthesiology in 2002, we reported that subdiaphragmatic instillation of lidocaine before pneumoperitoneum is effective in the control of pain and to attenuate physiologic changes during pneumoperitoneum [4]. In a conference meeting of Endoscopic and Laparoscopic Surgeons of Asia in 2006, I presented "The best strategy for severe acute cholecystitis" and recommended that if the patients don't have critical comorbidity, it is better to try LC as early as possible. For elderly patients with critical comorbidities, I recommended percutaneous transhepatic gallbladder drainage rather than emergency surgery [5,6]. In 2008, I shared my trials to treat common bile duct (CBD) and intrahepatic duct (IHD) stones in my presentation titled, "Troubleshooting HBP laparoscopic surgery" at the Korean Surgical Society. For big CBD stones that could not be removed with endoscopic retrograde cholangiopancreatography with sphincterotomy before 2002, I used the gasless abdominal wall lifting system to try removing these stones (gasless laparoscopic CBD exploration) and placed the T-tube as done in open surgery. With the gasless lifting system, we could use open surgery instruments. After this initial experience, I modified the gasless laparoscopic $\mathrm{CBD}$ exploration to laparoscopic $\mathrm{CBD}$ exploration with an internal stent. With this modification, we did not need to insert the T-tube. To remove IHD stones, I used a cholangioscopy-guided electrohydraulic lithotripsy machine under the gasless abdominal wall lifting system. Currently, I am using ureteroscopy with the holmium laser lithotripsy machine which was developed to destroy ureteral stones because of its excellent power and image quality.

\section{Transition from laparoscopic-assisted to totally laparoscopic hepatectomy including living donor hepatectomy}

In our hospital, we started open liver resection in 1988, laparoscopic-assisted and total laparoscopic liver resection in 2002, and pure laparoscopic donor hepatectomy in 2019. When I performed a hand-assisted laparoscopic right hemihepatectomy in 2002 (Fig. 2), about 200 laparoscopic hepatectomies had been reported from 1991 to 2001 in the literature; 102 resections were performed for malignant tumors and 84 for benign tumors. At that time, we were afraid of gas embolism and had doubts about the oncologic safety and feasibility in major liver resection. In 2004 and 2007, I presented my trials for the laparoscopic hepatectomy (pitfalls, experience, and how I did) at the Korean Surgical Society. In 2008, under the title, "Transition from open to laparoscopy in liver surgery", I presented my experience with the learning curve of my junior colleague and concluded that laparoscopic hepatectomy could be a safe, easy, and standard technique [7]. In 2009, we shared our experience before establishing total laparoscopic liver resection as a standard operation and published the papers "Rationale and surgical technique of laparoscopic left lateral sectionectomy using endoscopic staples" and "Laparoscopic liver

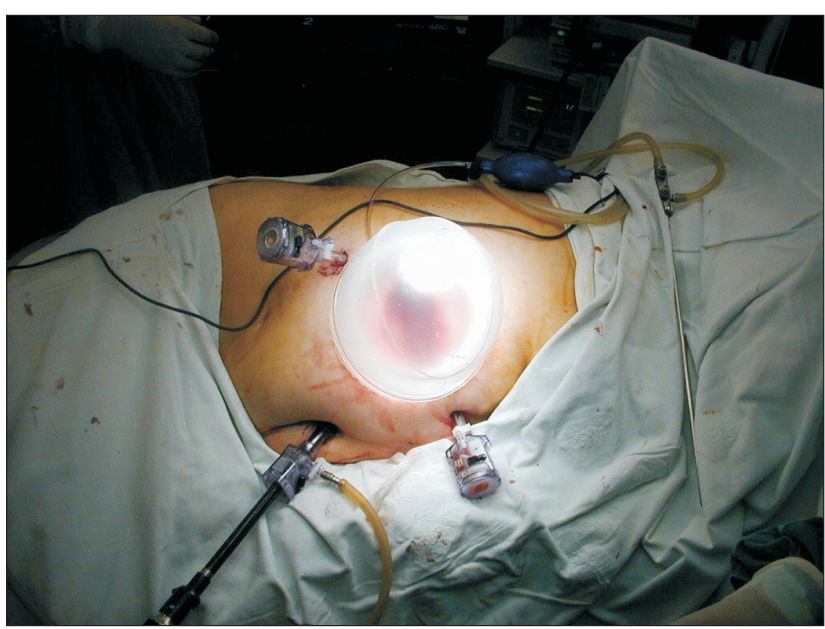

Fig. 2. Hand-assisted laparoscopic right hemihepatectomy performed in 2002. 
resection for malignant liver tumors, why not more?" in the Annals of Surgical Treatment and Research [8-11]. The total number of laparoscopic liver resections in my hospital before 2020 was 377, including 43 major liver resections and 151 anatomical liver resections [12]. In April 2019, one of my young colleagues started the pure laparoscopic donor hepatectomy and performed seven right donor hepatectomies and one right posterior donor hepatectomy.

\section{Strategies to reduce bleeding and pancreatic fistula in laparoscopic distal pancreatectomy}

Currently, we are performing three kinds of laparoscopic distal pancreatectomy (DP) such as conventional DP, spleen preserving DP, and Warshaw operation (cut the splenic vessels but preserve the spleen by saving blood vessels between the spleen and the stomach). During the first time, I tried conventional DP using the open retrograde technique (Fig. 3), I experienced bleeding and postoperative pancreatic leakage. After several rounds of trial and error, I set up my own techniques: antegrade conventional DP, spleen preserving DP, and Warshaw operation. In 2008 and 2010, I gave two presentations titled, "Laparoscopic distal pancreatectomy, how I do it?" and "Laparoscopic spleen preserving distal pancreatectomy" at the Korean Surgical Society. In 2012, I also gave a presentation titled, "Strategy to reduce bleeding and pancreatic fistula during laparoscopic DP." To prevent bleeding from the splenic vein during spleen preserving DP, I recommended three surgical tips at that time: (1) try to expose the splenic vein as long as possible; (2) apply a vascular clamp to the splenic vessel, if possible; (3) convert to Warshaw operation or conventional laparoscopic DP in the case of massive bleeding, not to control. Furthermore, I discovered the reason why we had pancreatic fistula after pancreatectomy in pancreatic duct anatomy. After magnifying the cutting surface of the pancreas

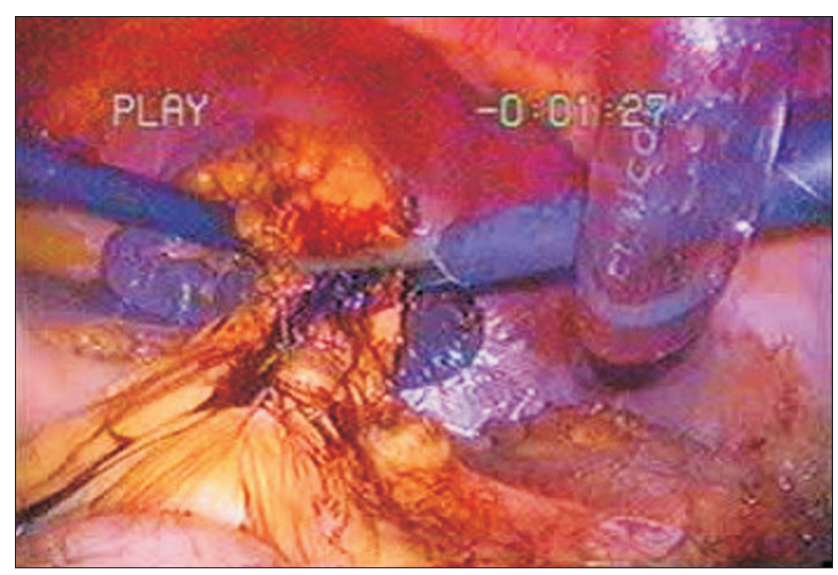

Fig. 3. My initial trial of conventional laparoscopic distal pancreatectomy using open retrograde technique. with a microscope, we can see the big main pancreatic duct in the near center and many minor pancreatic ducts around the main pancreatic duct (Fig. 4). Some of the minor pancreatic ducts are coming in or coming out from the cutting surface. With this anatomic understanding, I recommended that it is better to close the stump as wide as possible (Fig. 5) with a careful closing technique, prefiring compression for 2 to 3 minutes at a steady speed, and holding it for another 2 minutes after firing. I also emphasized the importance of the adequate staple which should be chosen depending on the parenchymal condition, whether it is thin, moderate, or thick with fibrosis or inflammation. Additionally, I recommended staple line reinforcement with clips and the application of fibrin glue at the staple line.

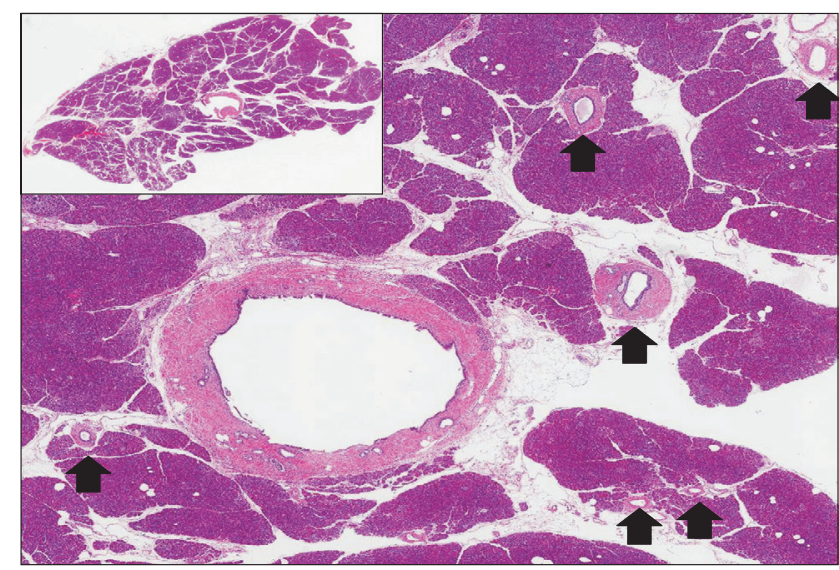

Fig. 4. The main pancreatic duct in the near center and many minor pancreatic ducts around the main (arrows). H\&E stain, $\times 1$ (inset, $\times 20$ ).

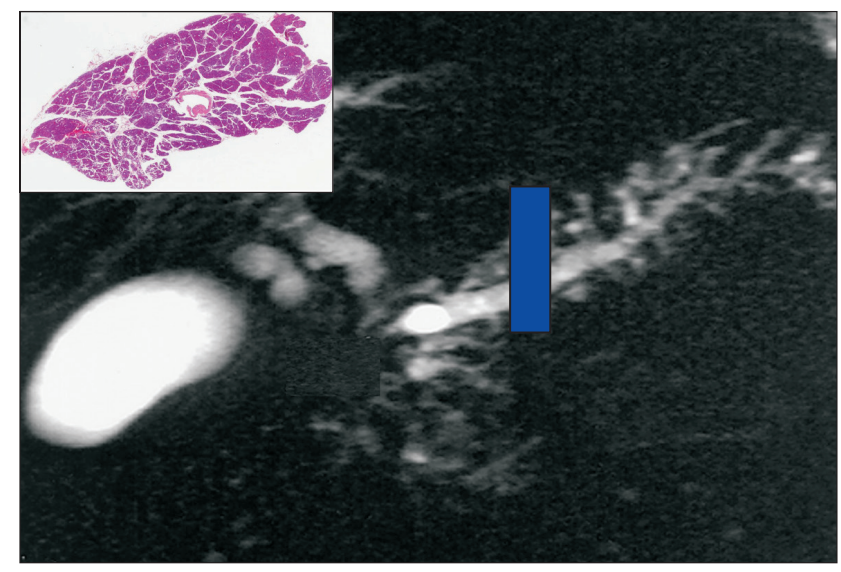

Fig. 5. The branching pattern of the 2nd and 3rd branches from the main pancreatic duct showing some of the minor ducts coming in or out from the cutting surface. inset: $H \& E, \times 1$. 


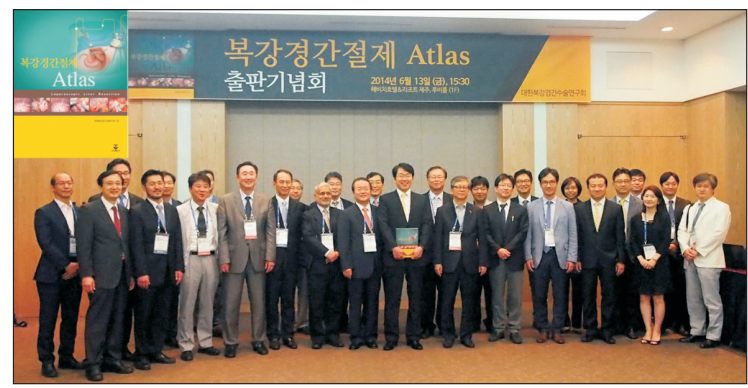

Fig. 6. The Korean Laparoscopic Liver Study Group published "Atlas Book of Laparoscopic Liver Resection [13]" in 2014.

\section{CURRENT STATUS IN KOREA (TWO ACTING STUDY GROUPS)}

\section{Laparoscopic Liver Surgery Study Group}

My first meeting with the Laparoscopic Liver Study Group was held in May 2008. This study group devoted many efforts to develop the surgical technique, including live surgeries and domestic and international symposiums, in addition to propagating and standardizing laparoscopic liver surgery in Korea. Eventually, they published "Atlas Book of Laparoscopic Liver Resection" in 2014 (Fig. 6) [13]. The contents of this book include non-anatomical liver resection in part $\mathrm{I}$, anatomical liver resection in part II, and donor and robotic hepatectomy in part III. All authors of this book are members of the Laparoscopic Liver Study Group.

\section{Korean Study Group of Minimally Invasive Pancreatic Surgery}

The first meeting of the Korean Study Group of Minimally Invasive Pancreatic Surgery was held in August 2019 and occurs on a quarterly basis (Fig. 7). Their purpose includes the communication of knowledge, information, and technique, and the improvement, standardization, and propagation of the minimally invasive pancreatic surgery procedure. After their meetings, they send the list of their presentations linked with YouTube by email. When the title is clicked, the presentation can be viewed online for free. They are trying to prepare a web-based education system for a starter. From 2007 to 2019, experts in nine Korean tertiary centers performed 1,526 cases of laparoscopic pancreaticoduodenectomy (PD). This year, I predict that more than 400 cases of laparoscopic PD will be done in Korea.

\section{FUTURE DIRECTION}

The mission of the Korean Society of Endoscopic and Laparoscopic Surgeons is to "Contribute to our community by saving

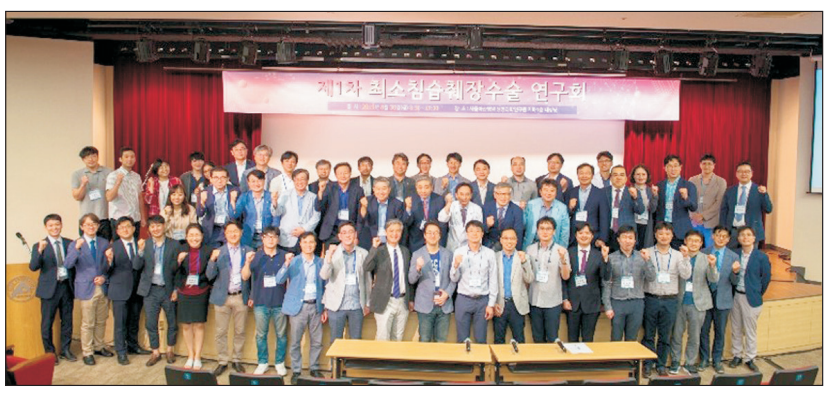

Fig. 7. The first meeting of the Korean Study Group of Minimally Invasive Pancreatic Surgery was held in August 2019.

and enriching patients' lives with painless and scarless surgery." As we know, our patients want to be cured in a way that is $100 \%$ safe, without any scars or pain. We are currently using singleport robotic and laparoscopic surgery. Even though we are not satisfied with current natural orifice transluminal surgery (NOTES), we will find a way to improve our current techniques as we always do. In the future, we may try NOTES first; if we fail, we will convert to single-port surgery. If we fail again, we will convert to laparoscopic surgery. We are living in the era of the fourth industrial revolution where artificial intelligence, robots, and virtual reality all have the potential to help us develop a new surgical platform for minimally invasive surgery.

\section{NOTES}

\section{Conflicts of interest}

The author has no conflicts of interests to declare.

\section{Acknowledgments}

To my teacher, Professor Koing Bo Kwun in the United States, I would like to express my sincere appreciation for his lifelong teaching.

\section{REFERENCES}

1. Noh HK, Yun SS, Kwak DM, et al. Endoscopic saphenous vein harvesting: minimally invasive video-assisted saphenectomy-clinical experience. J Minim Invasive Surg 2001;4:38-42.

2. Noh HK, Yun SS, Kwak DM, Kwun WH, Kim HJ, Suh BY. Endoscopic technique for subfascial perforator vein interruption in chronic lower leg deep vein insufficiency-clinical experience. J Minim Invasive Surg 2001;4:43-47.

3. National Institutes of Health Consensus Development Conference Statement: Gallstones and Laparoscopic Cholecystectomy. September 14-16, 1992. J Laparoendosc Surg 1993;3:77-90. 
4. Song SO, Park SY, Kim HD, et al. The effects of intraperitoneal instillation of lidocaine before pneumoperitoneum on postoperative pain score and intraoperative changes of blood pressure in patients with a laparoscopic cholecystectomy. Korean J Anesthesiol 2002;43:625-632.

5. Kim GW, Yun SS, Kim DS, et al. The results of laparoscopic cholecystectomy in acute cholecystitis. J Korean Surg Soc 1998;55:576-582.

6. Kim JS, Kwun WH, Yun SS, Kim HJ, Kwun KB. Results of 2,000 laparoscopic cholecystectomies at the Yeungnam University Hospital. J Minim Invasive Surg 2001;4:16-22.

7. Lee DS, Cui ML, Kim HJ, Yun SS. Gaining experience before establishing a totally laparoscopic left lateral sectionectomy as a standard procedure. Korean J Hepatobiliary Pancreat Surg 2010;14:149-153.

8. Son SH, Kim HJ, Yun SS, Lee DS, Lee DH. Single center experience of laparoscopic hepatectomy: the comparison of perioperative outcomes between early and late period. Korean J Hepatobiliary Pancreat Surg
2012;16:7-12.

9. Kwon IS, Yun SS, Lee DS, Kim HJ. Laparoscopic liver resection for malignant liver tumors, why not more?. J Korean Surg Soc 2012;83:30-35

10. Hwang DW, Han HS, Yoon YS, et al. Laparoscopic major liver resection in Korea: a multicenter study. J Hepatobiliary Pancreat Sci. 2013;20:125-130.

11. Lee BH, Yun SS, Kim MK, Jung HK, Lee DS, Kim HJ. Rationale and surgical technique of laparoscopic left lateral sectionectomy using endoscopic staples. Ann Surg Treat Res 2014;87:66-71.

12. Lee SY, Lee DS, Yun SS, Cho CW. A comparison of short-term outcomes between laparoscopic and open liver resection in elderly patients. J Minim Invasive Surg 2020;23:179-185.

13. Korean Laparoscopic Liver Surgery Study Group. Atlas book of laparoscopic liver resection. Seoul: Koonja Publishng; 2014. 